\title{
Control del pensamiento, esfuerzo cognitivo y lenguaje fisionómico-organísmico: tres manifestaciones expresivas del lenguaje interior en la experiencia humana*
}

\section{Thought Control, Cognitive Effort and Physiognomy-Organismic Language: Three Expresive Manifestations of Inner Language at Human Experience}

\author{
PABlo Fossa ${ }^{\mathrm{a}}$ \\ Universidad del Desarrollo, Chile \\ ORCID: http://orcid.org/0000-0002-9975-8537 \\ Natalia Awad \\ Universidad del Desarrollo, Chile \\ FABIÁn RAmos \\ Universidad de La Serena, Chile \\ Yerko Molina \\ Universidad Adolfo Ibañez, Chile \\ ORCID: http://orcid.org/0000-0002-9117-3606 \\ Sofía de la Puerta \\ Universidad del Desarrollo, Chile \\ ORCID: http://orcid.org/0000-0003-3557-949X \\ Carlos Cornejo \\ Pontificia Universidad Católica de Chile, Chile \\ ORCID: http://orcid.org/0000-0001-5426-0025
}

\footnotetext{
a Autor de correspondencia. Correo electrónico: pfossaa@udd.cl
}

Para citar este artículo: Fossa, P., Awad, N., Ramos, F., Molina, Y., de la Puerta, S., \& Cornejo, C. (2018). Control del pensamiento, esfuerzo cognitivo y lenguaje fisionómico-organísmico: tres manifestaciones expresivas del lenguaje interior en la experiencia humana. Universitas Psychologica, 17(4), 1-15. https://doi.org/10.11144/Javeriana.upsy17-4.c pec

\section{RESUMEN}

El presente artículo reporta los resultados de un estudio cuantitativo exploratorio, cuyo objetivo fue identificar formas de lenguaje interior y sus manifestaciones expresivas en la gestualidad. Los participantes, 50 estudiantes universitarios, fueron sometidos individualmente a dos eventos de elicitación de lenguaje interior: una música instrumental y un cuento. Luego de cada estímulo, se les solicitó reflexionar en silencio los contenidos elicitados por cada uno, para posteriormente participar en una entrevista cualitativa videoasistida. Las categorías gestuales fueron codificadas y analizadas a través de un análisis estadístico descriptivo, correlaciones de Pearson y análisis de componentes principales. Los resultados evidencian tres formas de lenguaje interior asociados a diferentes movimientos expresivos no verbales. En primer lugar, aparece un lenguaje interno al servicio del control del pensamiento, asociado a movimientos no verbales de control y búsqueda voluntaria del pensamiento. En segundo lugar, un lenguaje interior de esfuerzo cognitivo, que implica gestos iterativos que manifiestan procesamiento de información. Finalmente, se observa un lenguaje interno fisionómicoorganísmico, asociado a expresiones no verbales que manifiestan una interioridad cargada de sentido. Estos hallazgos contribuyen a la 
comprensión de la formación de símbolos, con la descripción de sus formas internas y externas, entendiendo la experiencia humana como única, total y holista.

Palabras clave

lenguaje interior; expresividad; lenguaje expresivo; gestos.

\begin{abstract}
The present article reports the results of a quantitative exploratory study whose objective was to identify interior language forms and its expressive manifestations in gestures. 50 university students were individually submitted to two events of inner language elicitation: an instrumental music and a story. After each stimulus participants were asked to reflect in silence the contents elicited by each stimulus, and then participate in a qualitative video-assisted interview. Gestural categories were coded and analyzed through descriptive statistical analysis, Pearson's correlation and principal component analysis. The results show three forms of inner language that are associated with different nonverbal expressive movements. First, there is an internal language at the service of the control of thought associated with nonverbal movements of control and voluntary search of thought. Second, there is evidence of a cognitive effort inner language, which involves iterative gestures that manifest information processing. Finally, an internal physiognomy-organismic language, associated with nonverbal expressions that manifest an interiority full of sense. These findings contribute to the understanding of the symbols formation, describing their internal and external forms, understanding the human experience as unique, total and holistic.
\end{abstract}

Keywords

inner language; expressiveness; expressive language; gestures.

El lenguaje interior constituye un lenguaje privado dirigido hacia sí mismo (Vygotsky, 1934). En los últimos años, ha existido un importante incremento del número de trabajos que han explorado este fenómeno (Dasilveira \& Gomes Barbosa, 2012; Damianova, Lucas, \& Sullivan, 2012; Seli, Risko, \& Smilek, 2016, entre otros). Distintos estudios han abordado diferentes dimensiones del fenómeno. Por ejemplo, la tradición vygotskyana ha comprendido el lenguaje interior como instrumento de la cognición, enfatizando específicamente la función reguladora y de resolución de problemas que tendría el lenguaje interior en la experiencia humana (Kinsbourne, 2000; Ruby, Smallwood, Sackur, \& Singer, 2013; entre otros). Por otro lado, la tradición dialógica ha priorizado la relación del lenguaje interior con el self, comprendiendo las múltiples voces en el lenguaje interno como múltiples posiciones subjetivas de la persona (Hermans \& Dimaggio, 2004; Hermans \& Hermans-Konopka, 2010). La tradición basada en la divagación mental (mind wandering) ha priorizado sus atributos de involuntariedad y ubicuidad en la experiencia como principales características del fenómeno (Smallwood \& Schooler, 2006; Seli et al., 2016; entre otros). Finalmente, la tradición que ha establecido la relación del lenguaje interior con gestos expresivos ha abordado principalmente el rol que estos tienen en la resolución de problemas académicos en el lenguaje interior (McCafferty, 2004; Zurina \& Williams, 2011, entre otros).

Vygotsky (1934) es tal vez el autor que mejor ha logrado sistematizar una aproximación a este fenómeno. Para este autor, el lenguaje interior constituye una forma de lenguaje que, si bien es independiente y diferenciado del vocalizado -debido a sus peculiaridades fonética, semántica y sintáctica-, corresponde al resultado evolutivo posterior de un proceso de progresiva internalización y abreviación del lenguaje social-comunicativo externo. Esto es, la palabra es dada por el mundo social y cultural, y está siempre cargada de sentido. Al internalizarse la palabra vocalizada y pasar a ser parte del lenguaje interior cambia algunas dimensiones que antes, en el lenguaje socialcomunicativo, mantenía. Fonéticamente, es un lenguaje silencioso, privado, no audible, lo que constituya la principal diferencia con el lenguaje externo. Por otro lado, su estructura sintáctica es también diferente. En el lenguaje interior existe una tendencia a la predicatividad, esto es, una tendencia a mantener los predicados y suprimir los sujetos: la persona sabe a quién está dirigido, es decir, el sujeto de la predicación. Finalmente, el lenguaje interior tiene una diferencia semántica con el lenguaje externo: está más cargado de sentido. La diferencia semántica entre lenguaje interno y externo se manifiesta en la capacidad de condensación del primero, ya que un concepto da cuenta de una gran idea, la cual debe ser desmenuzada en diferentes frases y oraciones cuando es traducida al lenguaje exterior. 
Vygotsky (1934) sostuvo que el habla interior desempeña una función cognitiva y de autorregulación del propio pensamiento y comportamiento. Es decir, el habla interior en la adolescencia y la vida adulta cumpliría funciones que en épocas evolutivamente precedentes eran propiedad del lenguaje egocéntrico, descrito por Piaget.

A partir de una influencia principalmente vygotskyana, el habla interior se ha estudiado con un importante énfasis en el control del pensamiento y la autorregulación. Por ejemplo, diferentes estudios se han centrado en explorar el rol que cumpliría el lenguaje interior en la resolución de problemas, específicamente de niños y adolescentes frente a problemas lógico-matemáticos (Damianova et al., 2012; Dasilveira \& Gomes Barbosa, 2012; Roberts, 1979; Villagrán, Navarro, López, \& Alcalde, 2002); el papel que tendría en la capacidad de ejecutar planes y tomar decisiones (Baddeley \& Hitch, 2000; Lidstone, Meins, \& Fenyhough, 2010); el rol en la lectura, la comprensión y la memoria (Abramson \& Goldinger, 1997; Baddeley \& Hith, 1974; Larsen, Schrauf, Fromholt, \& Rubin, 2002; Sokolov, 1972); la neuroanatomía del lenguaje interior y las zonas cerebrales involucradas (Girbau, 2007; Morin, 2005; Morin \& Hamper, 2012); el habla interior y su función en el desarrollo de múltiples self (Bakthin, 1981, 1984; Hermans \& Dimaggio, 2004; Hermans \& Hermans-Konopka, 2010), entre otros. Finalmente, existen trabajos que han intentado completar el modelo teórico del fenómeno del lenguaje interior, evidenciándose en algunos de ellos un intento por abordar, a nivel teórico, otras posibles funciones del fenómeno diferentes a la resolución de problemas y control del pensamiento (Cresswell, 2013; Fossa, 2017; Rosenthal, 2012).

$\mathrm{Si}$ aceptamos la hipótesis vygotskyana referida a que el lenguaje interior sería una internalización de un lenguaje socialcomunicativo propio de las primeras etapas de la vida, es posible pensar que el lenguaje interno como particular forma de lenguaje también es desplegado con microconductas no verbales que acompañan su expresión. Es decir, comprendiendo la expresión humana (de palabras y gestos) como un solo acto comunicativo, es plausible pensar en la existencia de gestualidad asociada a los eventos de lenguaje interior. Sin embargo, los estudios de lenguaje interior se han centrado solo en su dimensión de lenguaje verbal, entendiendo el lenguaje en su comprensión clásica de discurso o texto, excluyendo su dimensión corporal no verbal, presente en todo acto de lenguaje humano, ya sea vocalizado o no vocalizado. Los escasos estudios que han abordado la dimensión de la corporalidad lo han hecho siempre desde el interés por explorar la función de resolución de problemas y la utilidad de la gestualidad en el desarrollo de diálogos internos cuando el pensamiento es controlado y dirigido hacia un determinado razonamiento (McCafferty, 2004; Zurina \& Williams, 2011; entre otros).

En la investigación contemporánea, surge un concepto similar al de lenguaje interior denominado divagación mental. Esta corresponde a una situación en la que el control ejecutivo es desplazado desde una tarea primordial hacia el procesamiento de información que sustenta un objetivo personal. Es un desplazamiento del pensamiento hacia otro foco de atención o línea argumental, incluso sin la consciencia de que la mente se ha desviado (Smallwood \& Schooler, 2006). Si bien divagación mental y lenguaje interior parecen un mismo fenómeno, una diferencia central entre ambos es la voluntariedad. El lenguaje interior, siguiendo la argumentación vygotskyana, está al servicio de un pensamiento directivo, controlado y voluntario. Por el contrario, la divagación mental, de acuerdo a la descripción de Smallwood y Schooler (2006), es absolutamente involuntaria.

La divagación mental mantiene ciertas similitudes en relación con el procesamiento controlado estándar; sin embargo, hay una diferencia importante. El procesamiento controlado se asocia generalmente con la búsqueda intencional de una meta. La divagación mental, sin embargo, a menudo se produce sin intención, o incluso sin la 
conciencia de que la mente se ha desviado (Smallwood \& Schooler, 2006, p. 946).

De esta manera, el fenómeno de hablarse a sí mismo ha sido estudiado desde distintas tradiciones, enfatizando cada una de ellas aspectos diferentes del mismo fenómeno. Por un lado, una tradición que se ha centrado en su carácter controlado y voluntario, como herencia de la tradición vygotskyana y, por otro lado, otra que ha enfatizado su carácter involuntario, sin intención, como desviación del pensamiento respecto de la tarea en ejecución, lo que alude en mayor medida al concepto de divagación mental.

Respecto a los énfasis diferentes que se la han otorgado al fenómeno, un estudio reciente ha encontrado evidencia de la existencia de un tipo de divagación mental intencional (Seli et al., 2016), a diferencia de lo propuesto por Smallwood y Schooler (2006), estableciendo la necesidad de estudiar con mayor profundidad el fenómeno y sus posibles dimensiones.

$\mathrm{Si}$ aceptamos que la divagación mental constituye un desvío del pensamiento, ya sea intencional o no intencional, corresponde plantear entonces que nos estamos refiriendo al mismo fenómeno. La divagación mental (consciente o no consciente, voluntaria e involuntaria) constituye una forma de hablarse a sí mismo. No obstante, si aceptamos la existencia de un lenguaje no intencional se abren nuevas posibilidades de comprender el fenómeno del lenguaje interior vygotskyano, Es decir, este, que enfatiza la función reguladora del pensamiento, correspondería a la denominada divagación mental intencional; mientras que la divagación mental no intencional podría corresponder entonces a otras formas no descritas -al menos no explícitamente- de lenguaje interior.

Los estudios actuales sobre divagación mental han asociado el fenómeno al pensamiento creativo (Baird et al., 2012), así como también a la resolución de problemas (Ruby et al., 2013). Por otro lado, otras investigaciones también han relacionado la divagación mental con accidentes automovilísticos (Knowles \& Tay, 2002), dificultades académicas (Risko, Anderson,
Sarwal, Engelhardt, \& Kingstone, 2012) y con alteraciones emocionales (Smallwood et al., 2003).

La evidencia científica entonces nos permite pensar que la divagación mental en la investigación contemporánea alude, al menos parcialmente, al fenómeno del lenguaje interior, descrito a comienzos del siglo XX por Vygotsky. Una de las importancias de la investigación moderna es que destaca nuevas funciones del lenguaje interior, más allá de su conocida función regulatoria (de carácter intencional), descritas actualmente como formas no intencionales del funcionamiento cognitivo.

En síntesis, los estudios en lenguaje interior han tenido una importante influencia vygotskyana, en el sentido que se ha enfatizado la función autorreguladora del fenómeno, subdimensionando la importancia de otras posibles funciones del fenómeno. Por otro lado, la investigación contemporánea ha distinguido formas intencionales y no intencionales de lenguaje interior, lo que sugiere otras dimensiones de la actividad cognitiva aún inexploradas por la investigación. Finalmente, los estudios respecto al fenómeno han enfatizado solo su dimensión verbal, no incorporando la expresividad gestual, que permitiría comprender el lenguaje interior no únicamente como una actividad cognitivalingüística, sino como una función de la expresión humana.

\section{La función expresiva del lenguaje humano}

Karl Bühler ha sido uno de los pioneros en psicología en explorar la dimensión expresiva del lenguaje humano. Para Bühler (1933, 1934), el lenguaje humano tendría una función expresiva y esta dimensión transciende el cuerpo humano manifestándose en gestos emotivos. Bühler (1934) agrega a las funciones del lenguaje humano previamente descritas en la literatura -a saber, representacional y apelativa- una función expresiva. El lenguaje humano tiene una capacidad referencial, es decir, de nominar y representar los objetos del mundo. Por otro 
lado, tiene una función de apelar al destinatario. Finalmente, existe una función expresiva, que permite conocer subjetividad del emisor. Esto es, a través de la función expresiva del lenguaje humano el emisor se presenta al mundo, en sus estados psicológicos y motivaciones más profundas.

En su trabajo, Teoría de la expresión, Bühler (1933) completa su comprensión de la expresividad humana con la inclusión de elementos corporales, aludiendo a una antigua tradición filosófica-antropológica de la expresión humana. Es decir, de acuerdo con el autor, la expresividad humana no solo se manifiesta en la expresión de signos lingüísticos, sino también en movimientos no verbales; comprende tanto los movimientos físicos como el habla, como una sola forma de comunicación, enfatizando una estrecha relación entre el lenguaje y la fisionomía. Para él, la expresión humana manifestada a través de los gestos tiene una considerable diferencia con su gemelo, el lenguaje. Las manifestaciones corporales están más cerca de la experiencia interna que el lenguaje, debido a que este último es una mediación de la experiencia a través de signos lingüísticos.

Una manifestación de la función expresiva del lenguaje humano es lo que Werner ha denominado lenguaje fisionómico. Para Werner (Werner, 1955; Werner \& Kaplan, 1963), el lenguaje mantiene una dimensión geométrica-técnica que permite describir el estado de cosas del mundo. Por otro lado, tiene una dimensión fisionómica pues involucra aspectos organísmicos; precisamente, sus estudios (Werner, 1955; Werner, 1956; Werner \& Kaplan, 1963) dan cuenta de ello. Desde la perspectiva de Werner y Kaplan (1963), las palabras usualmente están fisionomizadas y su percepción produce una experiencia organísmica antes que puramente lingüística, por lo cual toda comprensión lingüística impone percepciones fisionómicas antes que su significado convencional geométrico-técnico. Así, una palabra nos puede parecer oscura, cálida, suave, etc., independientemente de su significado convencional. La naturaleza expresiva del lenguaje humano se manifiesta especialmente en su carácter fisionómico y su involucramiento en la gestualidad que acompaña el uso del lenguaje (Cornejo, Olivares, \& Rojas, 2013).

$\mathrm{Si}$ retomamos entonces el argumento vygotskyano respecto a que el lenguaje interior es el resultado de una internalización del lenguaje externo y si, por otro lado, consideramos las dimensiones expresivo-fisionómicas del lenguaje humano, es posible pensar que estos aspectos están presentes también en cada acto de lenguaje interior, y que su vez, este podría involucrar no solo signos lingüísticos, sino también expresiones gestuales.

En el presente estudio, se intenta explorar formas de lenguaje interior y sus manifestaciones expresivas en la gestualidad. Se propone que existirán diferentes formas de lenguaje interior asociadas a manifestaciones expresivas gestuales particulares. Esto daría cuenta de la posibilidad de que la experiencia del lenguaje interior incluya gestos expresivos, además de signos verbales.

\section{Método}

Se realizó un estudio cuantitativo de tipo transversal, con un diseño exploratorio correlacional, con el propósito principal de evaluar la asociación entre formas de lenguaje interior y sus manifestaciones gestuales. El estudio fue conducido en el Laboratorio de Interacción Lenguaje y Fenomenología (LIF) de la Pontificia Universidad Católica de Chile. Participaron 50 estudiantes de la carrera de Psicología de dicha universidad, 16 hombres y 34 mujeres, cuyas edades fluctuaron entre los 18 y 24 años. Todos los participantes firmaron un consentimiento informado aprobado por el Comité de Ética de la Dirección de Investigación de la misma Universidad, en el cual declaran su participación voluntaria en el estudio y su aceptación de ser grabados con fines de investigación con cámaras digitales de alta definición. Como compensación por participar del estudio, se les entregó a los estudiantes un bono de almuerzo.

Todos los participantes completaron el Mind Wandering Questionnaire ([MWQ]; Mrazek, 
Phillips, Franklin, Broadway, \& Schooler, 2013), escala que ha mostrado coherencia interna, validez y confiabilidad en muestras norteamericanas, y que se utiliza como un registro cuantitativo del nivel de divagación mental. Este cuestionario tiene cinco ítems con seis alternativas de respuestas que van desde la calificación nunca hasta siempre, siendo el punto de corte entre un alto nivel de divagación mental y uno bajo los 17.5 puntos. Se utilizó una traducción al español del instrumento, realizada por el investigador principal del estudio. Los cinco ítems del MWQ son los siguientes: "Tengo dificultad para mantenerme concentrado en una tarea fija o repetitiva"; "Mientras leo, me encuentro no pensando en el texto y debo volver a leerlo"; "Hago cosas sin poner total atención"; "Me encuentro a mí mismo escuchando con una oreja y pensando sobre otra cosa al mismo tiempo" y "Mi mente divaga cuando estoy en conferencias o presentaciones". Si bien el presente estudio buscó explorar tipologías de lenguaje interior y sus presentaciones en la gestualidad, se utilizó una medida cuantitativa el MWQ- para obtener un dato general respecto al nivel de divagación mental con que cuentan los participantes, con objetivo de explorar posibles diferencias entre niveles altos y bajos de actividad mental interior.

El procedimiento consistió en dos fases. En un primer momento, se solicitó a los participantes escuchar una música instrumental de 4 minutos de duración, en ausencia del investigador. La pieza seleccionada para el estudio fue la composición clásica The Unanswered Question de Charles Ives, debido a que pertenece a un género musical no totalmente conocido para los participantes y presenta variaciones entre segmentos de sonidos suaves y lentos mezclados con irrupciones bruscas de instrumentos de viento, lo que permite observar la experiencia y pensamientos internos durante a los cambios de sonido. Al finalizar la pieza, los participantes recibían de manera escrita la instrucción de reflexionar durante tres a cinco minutos en silencio la pregunta: "¿Qué pensaste durante la música?"
La segunda fase del procedimiento consistió en invitar a los participantes a leer un cuento, el cual era proyectado en un monitor al interior del laboratorio. El cuento seleccionado fue Pacto de sangre de Mario Benedetti. Luego de la lectura del cuento los participantes recibieron la instrucción de reflexionar en silencio durante tres a cinco minutos la siguiente pregunta: "¿Cómo impacta este cuento en tu propia historia?". Los estímulos escogidos para ambas fases del estudio (pieza musical y cuento) tuvieron por objetivo elicitar eventos de lenguaje interno. Los criterios para seleccionar estos estímulos se basaron en su carácter introspectivo y su extensión temporal, características que permitieron que los participantes entraran en un estado propicio para el diálogo consigo mismo.

Al finalizar la reflexión de cada una de las fases del procedimiento, un colaborador ingresaba al laboratorio para realizar una entrevista cualitativa videoasistida (Halford \& Sanders, 1990; Waldron \& Cegala, 1992), técnica que ha sido utilizada en trabajos empíricos para el estudio de diferentes procesos cognitivos con objetivo de evidenciar el flujo del pensamiento de manera retrospectiva. Los estudios que hacen uso de ella implican la realización de una tarea específica y posteriormente se realiza la entrevista, en la cual reviven pensamientos y sentimientos experimentados previamente mientras observan la reproducción del video del procedimiento anteriormente realizado.

Un investigador del equipo entrevistó a cada participante revisando los últimos minutos de la cinta de video en cada uno de los estímulos, esto es, cuando el estímulo ya había terminado y el participante aparecía en el registro reflexionando en silencio. Esta entrevista tenía por objetivo indagar pensamientos internos en diferentes movimientos no verbales del participante, manifestados en el registro de video. Estos contenidos del pensamiento permitieron observar funciones y dimensiones del lenguaje interior, los cuales fueron codificados y conformaron un protocolo de análisis del lenguaje interior y gestos expresivos. El tiempo de duración de las entrevistas fue de entre 3 a 10 minutos, según la duración de cada registro. 
A diferencia de los estudios previos, el procedimiento del presente estudio incorpora al participante como parte del análisis. Esto es, es el mismo participante quien observándose en el video relata los pensamientos internos, asumiendo que es el propio participante quien puede elaborar reconstructivamente el flujo de su lenguaje interior.

\section{Análisis de datos}

Para el estudio, se utilizó un diseño no experimental, transversal descriptivocorrelacional, sobre dos unidades de análisis diferenciadas según tipo lógico, a nivel de sujetos y a nivel de cuadros, sobre un mismo procedimiento. La muestra empleada se constituyó utilizando una estrategia no probabilística que incluyó a 50 sujetos, quienes fueron expuestos a un procedimiento de elicitación de lenguaje interior (una pieza musical instrumental y la lectura de un cuento). La recolección de datos consistió en editar los registros de video y analizar los movimientos gestuales y formas de lenguaje interior desplegados, codificando categorías gestuales y de lenguaje interior emergentes en cada momento del video, según la siguiente descripción:

- Mirada oscilante

Movimiento ocular sacádico rápido y de corta duración (foco en diferentes puntos del campo visual alternando la posición de la mirada en línea recta y de manera rápida, en todas las direcciones posibles del plano horizontal y vertical). En general, la cabeza se mantiene estática y solo se evidencia movimiento ocular. En ocasiones, la cabeza cambia de posición, manteniéndose estática en su nueva ubicación, mientras el movimiento ocular es permanente.

- Mirada perdida

Mirada fija y estática con un pronunciado abrir de párpados.

- Gesto súbito

Movimiento repentino y solitario que marca un quiebre en el comportamiento general. Puede involucrar diferentes partes del cuerpo. Su carácter repetino y brusco establece un cambio en la gestualidad. No es repetitivo, sino que es desplegado en un solo momento y por una única vez (p. ej., golpear el muslo con la mano, chasquido de dedos, etc.).

- Gesto iterativo

Movimiento repetitivo de cualquier parte del cuerpo (p. ej., contar con los dedos o golpear una mano sucesivas veces con la otra).

- Contracción de ojos

Cerrar de ojos que puede ser intermedio (parpados levemente cerrados pero manteniendo la mirada), total (parpados totalmente cerrados), forzada (parpados cerrados y con evidente fuerza).

- Contracción de ceño

Movimiento en que las cejas se juntan.

- Vocalización

Movimiento de boca como hablando. Puede ser con sonido audible o simple vocalización sin sonido audible.

- Asentimiento

Movimiento de cabeza característico de la aprobación (de arriba hacia abajo).

- Negación

Movimiento de cabeza de izquierda a derecha o viceversa.

Algunas de estas categorías fueron excluyentes entre sí, como por ejemplo las categorías relacionadas con la forma de la mirada (a saber, mirada perdida y mirada oscilante), mientras todas las otras categorías podían ser codificadas en una misma expresión gestual.

Respecto de las categorías asociadas a las formas del lenguaje interior se utilizó la siguiente clasificación:

- Recuerdo

Referencia explícita a un recuerdo de la propia vida.

- Lenguaje denotativo

Forma de lenguaje conceptual y declarativo cuyo objetivo es transmitir información (p. ej., En ese momento estaba pensando en si el personaje principal había sido veterano de guerra o no...).

- Lenguaje expresivo

Forma de lenguaje con contenidos esféricos y globales, difusos y con sensaciones organísmicas (p. ej., En ese momento se me vino a la mente 
algo sublime, como flotante, como una sensación de oceanidad...).

\section{- Lenguaje voluntario}

Forma de lenguaje que evidencia una dirección específica del pensamiento. Es una forma de lenguaje controlado y consciente. El sujeto sabe que está realizando una actividad mental interior y realiza un esfuerzo voluntario para no desviar el pensamiento (p. ej., En ese momento estaba tratando de recordar lo que ocurrió el fin de semana...).

\section{- Lenguaje involuntario}

Forma de lenguaje que evidencia una emergencia espontánea del pensamiento (p. ej., No sé por qué en ese momento pensé en una familia...).

- Imágenes mentales

Lenguaje en que se describen imágenes o escenas, que dan cuenta de la capacidad de imaginación. (p. ej., En ese momento me imaginé un bosque con agua corriendo por un río...).

- Emoción

Referencia explícita a una emoción (p. ej., En ese momento me acordé de mi abuelo y me dio mucha pena...).

- Destinatario

Refiere al destinatario del diálogo interno. Puede ser otro o sí mismo (p. ej., En ese momento me preguntaba por qué siempre pienso en cosas terribles...).

- Temporalidad

Se refiere a la orientación temporal del lenguaje interior. Puede ser un habla interior dirigida hacia el tiempo pasado (recuerdo), presente (en el aquí y ahora) o una proyección hacia el futuro (imaginación).

Algunas de estas categorías fueron excluyentes entre sí: lenguaje denotativo y lenguaje expresivo, así como lenguaje voluntario y lenguaje involuntario. Todas las otras categorías podían haber sido codificadas junto con otras en una misma expresión.

Para el registro de los datos, dos jueces fueron entrenados en el protocolo de gestos construido a partir de las categorías emergentes en el análisis videográfico para que codificaran los registros de video, sin conocer los contenidos de la entrevista videoasistida (categorías verbales).
Así, los jueces codificaron exclusivamente los gestos desplegados, sin tener acceso al audio de dichos tramos de video. Luego de un entrenamiento, los jueces codificaron todos los registros segmentados en pequeños marcos de 10 segundos de tiempo, registrando los gestos descritos de manera dicotómica $(1=$ aparece el gesto y $0=$ no aparece el gesto). Para evaluar la confiabilidad desde el criterio de congruencia interexaminadores, se calculó un estadístico de kappa multivariado cuyo resultado fue 0.89 , evidenciando un nivel de acuerdo elevado entre los examinadores. Además de lo descrito, cada uno de los participantes contestó el cuestionario Mind Wandering Questionnaire (MWQ), que registró el nivel de divagación metal. El cuestionario fue validado por Mrazek et al. (2013), arrojando un alfa de Cronbach de 0.95 .

Respecto del análisis de datos, el resultado del registro de la información se concretó en dos bases de datos: una para el tipo lógico "individuo" donde se registró la proporción de emergencia de cada uno de los gestos y categorías de lenguaje interior analizados para cada sujeto del estudio según cada fase (Fase $\mathrm{A}=$ pieza musical; Fase $\mathrm{B}=$ lectura de cuento) y los puntajes para el MWQ $(n=50)$ y otra para el nivel lógico "cuadro" donde se registraron para cada cuadro de 10 segundos los gestos y categorías verbales codificados dicotómicamente $(n=1.709)$.

El análisis a nivel de "individuo" contempló una comparación entre las proporciones de emergencia de cada variable según el estímulo (música y cuento), para lo que se utilizó la prueba z para comparación de proporciones. Además de esto, se calcularon correlaciones de Pearson entre las proporciones para todos los gestos, con el objetivo de explorar patrones a nivel de los individuos en la emergencia de los gestos durante actos de lenguaje interior; en este sentido, el objetivo de este análisis fue observar si a nivel de individuo ciertos gestos tienden a emerger en conjunto con categorías de lenguaje interior, utilizando como criterio la frecuencia relativa de aparición frente un estímulo estándar. Para todos estos análisis, se utilizó un error de tipo 1 criterio de 0.05 para rechazar la hipótesis nula (confianza 
de un $95 \%$ ) y fueron ejecutados en el programa SPSS versión 20.

El análisis a nivel de "cuadro" se llevó a cabo utilizando un análisis de componentes principales, con el objeto de explorar si ciertos gestos (variables no verbales) tienden a aparecer en congruencia con formas o tipos de lenguaje interior (variables verbales). El análisis de componentes principales se efectuó sobre una matriz policórica, debido a la naturaleza dicotómica de los gestos y las categorías de lenguaje no verbal, que impedía utilizar el análisis tradicional sobre una matriz de correlaciones de Pearson. Para evaluar la adecuación de la matriz policórica, se utilizó la prueba de esfericidad de Bartlett y el estadístico de Kaiser-Meyer-Olkin (KMO), empleando los criterios tradicionales de adecuación (prueba de Bartlett con p menor a 0.05 y KMO sobre 0.5 como mínimo aceptable). El análisis estadístico para esta etapa se llevó a cabo utilizando el programa FACTOR.

\section{Resultados}

Los resultados descriptivos del MWQ muestran una media de 16.5 puntos y una desviación estándar de 3.64 puntos. Además, se evidencia que el $34 \%$ de los participantes presenta una alta divagación mental y un $66 \%$ de ellos presenta un nivel bajo.

Respecto a los análisis a nivel de "individuo" las comparaciones según fase (estimulo no verbal vs. estímulo verbal) se presentan en la Tabla 1 , con las proporciones promedio de emergencia los gestos y categorías verbales estadísticamente significativos separados por fase y el valor del estadístico de prueba y la probabilidad de error de tipo 1 observada.
Tabla 1

Comparación de proporciones para los gestos y

categorías verbales según fase

\begin{tabular}{lrrrc}
\hline Gesto o categoría proporción & P fase A & P fase B & \multicolumn{1}{c}{ Z } & $p$ \\
\hline Mirada oscilante & 0.535 & 0.743 & -4.334 & $<0.05$ \\
Contracci teboca & 0.121 & 0.217 & -2.882 & $<0.05$ \\
Suspiro & 0.028 & 0.066 & -2.641 & $<0.05$ \\
Estiramiento & 0.005 & 0.032 & -2572 & $<0.05$ \\
Recuerdo & 0.05 & 0.233 & -3.827 & $<0.05$ \\
Emocirdo & 0.048 & 0.282 & -4.53 & $<0.05$ \\
Involuntario & 0.056 & 0.234 & -3.86 & $<0.05$ \\
Otro & 0.014 & 0.219 & -4.764 & $<0.05$ \\
Pasado & 0.054 & 0.177 & -2.661 & $<0.05$ \\
Futuro & 0.001 & 0.039 & -2.446 & $<0.05$ \\
\hline
\end{tabular}

La Tabla 1 evidencia mayor proporción de variables (verbales y no verbales) en la Fase B del estudio (lectura de cuento), lo que nos permite comprender que el estímulo si es importante al momento de la elicitación de lenguaje interior.

Por otro lado, la comparación de proporciones permite observar algunas diferencias importantes. Los participantes que despliegan un acto de lenguaje interior orientado al recuerdo de alguna experiencia personal tienen mayor proporción de autoadaptadores $(\mathrm{P}=0.63)$ que los que no refieren recuerdo $(\mathrm{P}=0.4)$ y esa diferencia es estadísticamente significativa $(z$ $=-6.219 ; p<0.05)$. Los participantes que dan cuenta de un lenguaje interior voluntario tienen mayor proporción de mirada oscilante $(\mathrm{P}=0.70)$ que los que no refieren un lenguaje voluntario $(\mathrm{P}=0.61)$ y esa diferencia es estadísticamente significativa $(z=-2.903 ; p<0.05)$. Por otro lado, los participantes que refieren un lenguaje interior expresivo presentan un mayor índice de mirada perdida $\mathrm{P}=0.24$ ) que los que no refieren un lenguaje expresivo $(P=0.12)$, y esa diferencia es también estadísticamente significativa $(z=$ -2.689; $p<0.05)$.

Los participantes que despliegan una mirada oscilante tienden a presentar un mayor porcentaje de lenguaje interior denotativo $(\mathrm{P}=$ 0.41) en comparación con los que no lo presentan $(\mathrm{P}=0.26)$, y esa diferencia es estadísticamente significativa $(z=-6.33 ; p<0.05)$. Asimismo, los que muestran un lenguaje interior voluntario presentan una mayor proporción de lenguaje denotativo ( $\mathrm{P}=0.88)$ que los que no reportan ese tipo de lenguaje interior $(\mathrm{P}=0.12)$, y esa diferencia es estadísticamente significativa $(z=$ -58.957; $p<0.05)$. 
Los sujetos que presentan gestos iterativos evidencian además una mayor proporción de lenguaje denotativo $(\mathrm{P}=0.47)$ que los sujetos que no despliegan gestos iterativos $(\mathrm{P}=0.35)$ y esa diferencia es estadísticamente significativa $(z$ $=-2.071 ; p<0.05)$. Los sujetos que despliegan un movimiento de mirada perdida presentan mayor proporción de imágenes mentales $(\mathrm{P}=$ 0.21) que los que no presentan movimiento de mirada perdida $(\mathrm{P}=0.11)$ y esa diferencia es estadísticamente significativa $(z=-3.5 ; p<$ 0.05).

Por otro lado, existe una correlación significativa y positiva entre el puntaje MWQ y vocalización con sonido $(r=0.349 ; p<0.05)$, así como también entre MWQ y vocalización sin sonido $(r=0.403 ; p<0.05)$. Por otra parte, este análisis evidencia una correlación significativa y positiva entre mirada oscilante y elevación de mirada $(r=0.243 ; p<0.05)$, contracción de ojos intermedia $(r=0.211 ; p<$ $0.05)$, contracción boca $(r=0.255 ; p<0.05)$ y el otro como destinatario del lenguaje interior $(r=0.242 ; p<0.05)$. De la misma manera, el movimiento de mirada perdida correlaciona de manera significativa y directa con imaginación $(r=0.201 ; p<0.05)$. Asimismo, las imágenes mentales correlacionan significativamente con un lenguaje interior expresivo $(r=0.399 ; p<$ 0.05). Por su parte, el movimiento de iteración correlaciona de manera significativa y directa con contracción de ojos forzada $(r=0.233 ; p<0.05)$, asentimiento $(r=0.361 ; p<0.05)$ y negación $(r$ $=0.294 ; p<0.05)$. Así mismo la presencia de un lenguaje interior voluntario correlaciona positiva y significativamente con un lenguaje denotativo $(r=0.671 ; p<0.05)$

Previo al análisis de componentes principales se realizaron dos pruebas para evaluar la factibilidad del análisis. La medida de KaiserMeyer-Olkin [KMO] arrojó 0.499 lo que indica que se cumplen las condiciones para indicar que las variables se pueden correlacionar. Por otro lado, la prueba de esfericidad de Bartlett entregó una significancia de $0(p<0.005)$, lo que permite asumir que las variables correlacionan entre sí.
Tabla 2

Prueba de Bartlett y KMO

\begin{tabular}{lcr}
\hline \multicolumn{3}{c}{ Prueba de Bartlett y KMO } \\
\hline Medida Kaiser-Meyer-Olkin de adecuación de muestreo & 0.499 \\
Prueba de Esfericidad de Bartlett & Aprox. chi-cuadrado & $12,78,147$ \\
& gl & 496 \\
& Sig. & 0 \\
\hline
\end{tabular}

El análisis de componentes principales, integrando las categorías verbales y no verbales, evidenció la presencia de cuatro conglomerados, los cuales explican en su conjunto un $53.5 \%$ de la variabilidad de la totalidad de las variables analizadas en este estudio. Las agrupaciones de componentes principales se describen en la siguiente tabla.

Tabla 3

Matriz de estructura de componentes principales

\begin{tabular}{|c|c|c|c|}
\hline 1 & 2 & 3 & 4 \\
\hline Súbito $(0.445)$ & $\begin{array}{c}\text { Mirada Oscilante } \\
\quad(0.755)\end{array}$ & $\begin{array}{c}\text { Iteración } \\
(0.694)\end{array}$ & $\begin{array}{c}\text { Mirada Perdida } \\
(0.308)\end{array}$ \\
\hline $\begin{array}{c}\text { Contracción Ojos } \\
\text { Intermedio } \\
(0.445)\end{array}$ & $\begin{array}{c}\text { Elevación Mirada } \\
(0.469)\end{array}$ & $\begin{array}{l}\text { Negación } \\
(0.749)\end{array}$ & $\begin{array}{c}\text { Contracción } \\
\text { Ojos Total } \\
(0.308)\end{array}$ \\
\hline $\begin{array}{l}\text { Denotativo } \\
(0.436)\end{array}$ & $\begin{array}{c}\text { Contracción Ojos } \\
\text { Intermedia }(0.387)\end{array}$ & $\begin{array}{l}\text { Asentimiento } \\
(0.653)\end{array}$ & $\begin{array}{l}\text { Expresivo } \\
(0.576)\end{array}$ \\
\hline $\begin{array}{l}\text { Voluntario } \\
(0.644)\end{array}$ & $\begin{array}{c}\text { Contracción Boca } \\
(0.486)\end{array}$ & & $\begin{array}{c}\text { Emoción } \\
(0.597)\end{array}$ \\
\hline Sí mismo (0.874) & $\begin{array}{c}\text { Contracción Ceño } \\
(0.337)\end{array}$ & & $\begin{array}{l}\text { Involuntario } \\
(0.635)\end{array}$ \\
\hline Presente $(0.769)$ & $\begin{array}{c}\text { Destinatario Otro } \\
(0.33)\end{array}$ & & \\
\hline
\end{tabular}

El análisis de componentes principales agrupa las variables del estudio (verbales y no verbales) en cuatro conglomerados. Es decir, existen perfiles conformados por variables de gestos y formas de lenguaje interior dentro de los participantes del estudio. Esto permite pensar que formas de lenguaje interior son co-ocurrentes con gestos expresivos específicos.

\section{Discusión}

Los resultados del presente estudio muestran la existencia de expresiones gestuales durante los eventos de lenguaje interior. En este sentido, el estudio evidencia formas de expresión no verbal que se desplieguen como microconductas observables co-ocurrentes con la experiencia interna del lenguaje. El análisis evidencia 
una coherencia entre la comparación de proporciones, la correlación de Pearson y el análisis de componentes principales. De esta manera, los resultados avalan la presencia de formas de lenguaje interior asociadas a movimientos expresivos no verbales.

El análisis intrasujeto, es decir, la comparación entre las fases A y B del procedimiento, arroja mayor presencia de expresiones verbales y no verbales en la segunda fase del estudio. Esto evidencia que la lectura del cuento, al ser un estímulo estructurado y con fuerte carga afectiva, elicitó formas de lenguaje denotativo, con despliegue de una mirada oscilante, basado en un recuerdo, con un destinatario imaginado distinto a sí mismo, involuntario, con vocalizaciones, que incluyó un despliegue afectivo en un tiempo pasado y también con proyecciones al futuro. Además, el cuento elicita movimientos de sonrisa y suspiros, así como también movimientos de bostezo y estiramiento, que podrían ser explicados por la extensión del cuento y el cansancio generado por el procedimiento de laboratorio en general.

Por otro lado, la primera fase del procedimiento, el estímulo musical, evidencia menos proporciones de categorías verbales y no verbales. Esto da cuenta de las características del estímulo, la pieza musical, que permitió, a través de una forma algo menos estructurada que el cuento, desplegar un lenguaje interior de diversas formas y con menos cantidad de movimientos no verbales.

Los resultados de este estudio sugieren tres formas distintas de manifestación del lenguaje interior. En primer lugar, demuestran la existencia de un control voluntario del pensamiento. Esta forma de lenguaje interior se caracteriza por ser denotativo, voluntario, con una direccionalidad consciente que da cuenta de una búsqueda cognitiva. Esta forma se expresa a través de gestos súbitos, una mirada oscilante, una contracción de ojos intermedia (los párpados de juntan, pero la mirada se mantiene oscilante), momentos de elevación de la mirada, junto con una contracción de boca y ceño. Esta forma de habla interna ha sido asociada al razonamiento y resolución de problemas, función clásicamente atribuida al lenguaje interior en los trabajos de Piaget (1922), Vygotsky (1934) y estudios contemporáneos del fenómeno (Damianova et al., 2012; Dasilveira \& Gomes Barbosa, 2012; Roberts, 1979; Villagrán et al., 2002; entre otros). Esta forma de manifestación es extraída de los componentes 1 y 2 en el análisis de componentes principales (Tabla 3), lo que, si bien es expresado como dos grupos independientes, su forma de manifestación fenomenológica da cuenta de un mismo y único fenómeno. La agrupación indica además que esta forma de lenguaje interior sería tanto dirigida a sí mismo como a otro, evidenciando que en la experiencia humana es posible hablarle en la mente a otro denotativamente, pero también existe el habla denotativa hacia sí mismo.

La segunda forma de lenguaje interior ha sido denominada esfuerzo cognitivo. Esta forma de lenguaje interior comparte el carácter denotativo -aunque con menos contenido explícito-, controlado, dirigido hacia sí mismo, dando cuenta de un esfuerzo cognitivo. Esta forma de lenguaje interior, a diferencia de la anterior, no tiene un contenido evidente, más bien, el sujeto está en una búsqueda del signo lingüístico, siendo dominado por esferas globales de significados. La palabra no aparece en el diálogo interior, más bien se busca con un esfuerzo cognitivo. En los datos del presente estudio, este tipo de lenguaje interior emerge durante el olvido, y su posterior esfuerzo de recordar, o durante la búsqueda de la palabra que se sabe y conoce, pero que no emerge en la consciencia cuando es requerida. Esta firma de lenguaje interior tiene expresión a través de gestos iterativos (Tabla 3, componente 3), contracción de ojos forzada, con presencia de movimientos de asentimiento y negación, caracterizado por un lenguaje interior denotativo y una voluntariedad en la ejecución del pensamiento, aunque sin un desarrollo de este, sino en una búsqueda de conceptos. Esta forma de expresión da cuenta de un procesamiento cognitivo, un pensamiento dirigido, voluntario e intencionado, con contenidos denotativos y una manifestación corporal expresiva de este procesamiento. 
Finalmente, los análisis realizados en este estudio señalan una tercera forma de habla interna que hemos denominado lenguaje fisionómico-organísmico. Esta forma de lenguaje interior (Tabla 3, componente 4), se caracteriza por la presencia de contenidos esféricos, difusos, mayor presencia de imágenes mentales, con involucramiento afectivo, vivido. Este lenguaje es involuntario, emerge en la experiencia en determinados momentos que no son controlados por el sujeto, y se manifiesta corporalmente a través de una posición estática, fijación de la mirada, con una forma de mirada perdida y contracciones de boca. En ocasiones, este fenómeno tiene lugar también con una contracción de ojos total (no forzada), lo que da cuenta de una experiencia ensimismada y conectada con una interioridad vivida y sentida.

Estos hallazgos permiten complementar los estudios en lenguaje interior y gestualidad, otorgando nuevas formas de manifestación del fenómeno y su expresión en el cuerpo. En este sentido, la forma de expresión asociada al control voluntario del pensamiento es coherente con la investigación previa que ha descrito formas de comportamiento no verbal desplegado en la resolución de tareas académicas, como por ejemplo, problemas matemáticos (Ruby et al., 2013; entre otros), como la presencia de gestos iterativos (i.e. contar los dedos), acompañados de movimientos de cabeza en forma de asentimiento o negación.

Por otro lado, la forma de expresión relacionada con el esfuerzo cognitivo apoya la tradición vygotskyana que ha declarado estas dimensiones como la principal función del lenguaje interior. Sin embargo, no han sido descritas en la literatura científica manifestaciones expresivas no verbales asociadas a esta función, lo que constituye un aporte de los presentes hallazgos.

Finalmente, se describe en este trabajo una fisionómica organísmica -aún escasamente explorada en la investigación modernarelacionada con formas globales y esféricas de significados, mayor presencia de imágenes mentales y con mayor dominio afectivo. Esta función presenta una forma de lenguaje menos denotativa, más bien difusa y difícil de referir declarativamente. En comparación con las otras formas de lenguaje interior previamente descritas, la dimensión expresiva-vivida es involuntaria e involucra mayor presencia de aspectos organísmicos (imágenes, sensaciones, formas, etc.), que manifiestan formas primitivas de lenguaje humano. Esta dimensión se asimila a lo que Werner y Kaplan (1963) describieron como lenguaje fisionómico.

Los hallazgos de esta investigación permiten corroborar la existencia de formas de lenguaje interior intencionales y no intencionales, en la misma dirección de lo que plantean Seli et al. (2016), aunque con algunos énfasis diferentes. Dichos autores proponen la existencia de una forma de lenguaje interior (mind wandering) intencional y no intencional. En los hallazgos de nuestro estudio, se puede apreciar que las formas de lenguaje intencional y no intencional (o más bien voluntario o involuntario, como ha sido denominado en el presente trabajo) difieren en un aspecto central. Aquí el habla voluntaria $-\mathrm{O}$ intencional- es principalmente denotativarepresentacional y el habla involuntaria $-\mathrm{O}$ no intencional-es principalmente expresiva-vivida. Si bien denotación y expresión constituyen aspectos inherentes a todo acto de habla interior, en los hallazgos se aprecian proporciones diferentes a cada momento de la experiencia, según sea desplegado una acción de control del pensamiento o se esté experimentando una interioridad vivida. Al parecer, entonces, las formas de lenguaje interior varían según la intencionalidad o voluntariedad que se le otorga al pensamiento, y en los resultados ha sido posible identificar un lenguaje interior intencional y denotativo, y otro no intencional y expresivo. Ambas formas de elaboración simbólica de la consciencia humana y su respectiva expresión en la gestualidad nos permiten observar el desarrollo de la formación de símbolos, y las formas internas y externas que adquiere el símbolo (Fossa, 2017).

Los hallazgos constituyen un aporte a la investigación sobre el fenómeno del lenguaje interior, y enfatiza la importancia de incluir la dimensión corporal en el estudio de los 
fenómenos relacionados con la consciencia humana.

\section{Conclusión}

Este estudio explora y describe diferentes formas de lenguaje interior y sus manifestaciones expresivas en la gestualidad. Los hallazgos sugieren la necesidad de considerar nuevas dimensiones y funciones del lenguaje interior, adicionales a las descritas clásicamente en psicología. Si bien la investigación se ha centrado principalmente en la función de razonamiento y control del pensamiento, la evidencia aquí encontrada sugiere que existen otras formas de lenguaje interior que no solo tienen la función de resolución de problemas. Esto desafía la comprensión única del lenguaje interior y el consenso existente respecto a su función y forma de expresión, y exige la emergencia de nuevos modelos comprensivos del fenómeno que permitan comprender toda su complejidad. En este sentido, centrar el interés científico en las formas de lenguaje interior involuntario -no intencional en el sentido de Seli at al. (2016)podría permitir conocer nuevas dimensiones/ funciones del fenómeno, complementando a la función de razonamiento, clásicamente estudiada en psicología.

Debido al tamaño muestral del presente estudio y la característica de los participantes, se sugiere que futuros estudios permitan comprobar estos hallazgos en una muestra mayor y más heterogénea. Por otro lado, los procedimientos realizados en el presente estudio (específicamente, la consigna para incentivar la reflexión posterior a los estímulos) podría haber intencionado formas de lenguaje interior reflexivas, controladas y reguladas, que dirigieran el pensamiento hacia la instrucción. Esto pudo haber determinado la emergencia de formas de lenguaje interior denotativa y voluntaria. Se sugiere que futuros estudios puedan triangular y contrabalancear las consignas utilizadas, para que los resultados y diferencias encontradas sean atribuidas solo a los estímulos y no a la variación de las consignas. Sin embargo, a pesar de esta limitación del procedimiento, se observaron formas de lenguaje expresivo-involuntario, lo que hace aún más relevante este hallazgo. Esto permite pensar en diseñar futuros procedimientos metodológicos que eliciten principalmente formas de lenguaje interior involuntario, menos reflexivas, lo que podría aportar importantes descubrimientos relacionados con el fenómeno.

Finalmente, los procedimientos permitieron observar la diferencia existente entre la experiencia del lenguaje interior y la capacidad de reportarla o tomar consciencia de su contenido y forma, lo que establece sin duda un gran desafío metodológico para futuras líneas de investigación interesadas en continuar explorando el fenómeno de la palabra y su relación con la consciencia humana.

\section{Referencias}

Abramson, M., \& Goldinger, S. (1997). What the reader's eye tells the mind's ear: Silent reading activates inner speech. Perception $\mathcal{E}$ Psychophysics, 59(7), 1059-1068. Recuperado de https://www.researchgate.net/publicatio n/13868338_What_the_reader\%27s_eye_ tells_the_mind\%27s_ear_Silent_reading_a ctivates_inner_speech

Baddeley, A., \& Hitch, G. (1974). Working memory. Psychology of Learning and Motivation, 8, 47-89. http://dx.doi.org/10.1 016/S0079-7421(08)60452-1

Baddeley, A., \& Hitch, G. (2000). Development of working memory. Journal of Experimental Child Psychology, 77, 128-137. http://dx.doi .org/10.1006/jecp.2000.2592

Baird, B., Smallwood, J., Mrazek, M. D., Kam, J. W., Franklin, M. S., \& Schooler, J. W. (2012). Inspired by distraction: Mind wandering facilitates creative incubation. Psychological Science, 23, 1117-1122. http:// dx.doi.org/10.1177/0956797612446024

Bakthin, M. (1981). The dialogic imagination. Austin: Texas University Press. 
Bakthin, M. (1984). Problems of Dostoesvsky's poetics. Minneapolis: Minnesota University Press.

Bühler, K. (1933). Theory of expression. Madrid: Alianza Editorial.

Bühler, K. (1934). Theory of Language. The representational function of language. Amsterdam: John Benjamins Publishing Company.

Cornejo, C., Olivares, H. \& Rojas P. (2013). The physiognomic and the geometrical apprehensions of metaphor. Culture $\mathfrak{E}$ Psychology, 19(4), 484-505. https://doi.org/ 10.1177/1354067X13500330

Cresswell, J. (2013). Experience and sociocultural psychodynamics: Comment on Larrain and Haye's "The discursive nature of inner speech". Theory EF Psychology, 23(1), 123-130. http://dx.doi.org/10.1177/ 0959354312457483

Damianova, M., Lucas, M., \& Sullivan, G. (2012). Verbal mediation of problem solving in pre-primary and junior primary school children. South African Journal of Psychology, 42(3), 445-455. http://dx.doi.or $\mathrm{g} / 10.1177 / 008124631204200316$

Dasilveira, A. C., \& Gomes Barbosa, W. (2012). Experiential perspective of inner speech in a problem-solving context. Paideia, 22(51), 43-52. http://dx.doi.org/10.1590/S0103-86 3X2012000100006

Fossa, P. (2017). Pleromatization, physionomization and metaphoricity: A theoretical articulation of sense making process of Valsiner, Werner and McNeill. Psicología USP, 28(1), 93-102. http://dx.doi .org/10.1590/0103-656420150181

Girbau, D. (2007). A neurocognitive approach to the study of private speech. The Spanish Journal of Psychology, 10(1), 41-51. Recuperado de http://revistas.ucm.es/index.php/SJOP/a rticle/view/SJOP0707120041A/28928

Halford, W. K., \& Sanders, M. R. (1990). Assessment of cognitive self-statements during marital problem solving: A comparison of two methods. Cognitive
Therapy and Research, 12, 515-530. http://d x.doi.org/10.1007/BF01173417

Hermans, H., \& Dimaggio, G. (2004). The dialogical self in psychotherapy. Nueva York: Routledge.

Hermans, H., \& Hermans-Konopka, A. (2010). Dialogical self theory: Positioning and counterpositioning in a globalizing society. Cambridge: Cambridge University Press.

Kinsbourne, M. (2000). Inner speech and the inner life. Brain and Language, 71, 120-123. http://dx.doi.org/10.1006/brln.1999.2229

Knowles, D., \& Tay, R. (2002). Driver inattention: More risky than the fatal four? En Proceedings of the 2002 Road Safety Research, Policing and Education Conference (pp. 87-91). Mawson, Australia: Australasian College of Road Safety.

Larsen, S., Schrauf, R., Fromholt, P., \& Rubin, D. (2002). Inner speech and bilingual autobiographical memory: A PolishDanish cross-cultural study. Memory, 10(1), 45-54. http://dx.doi.org/10.1080/09658210 143000218

Lidstone, J., Meins, E., \& Fernyhough, C. (2010). The roles of private speech and inner speech in planning during middle childhood: Evidence from a dual task paradigm. Journal of Experimental Child Psychology, 107, 438-451. http://dx.doi.org/ 10.1016/j.jecp.2010.06.002

Morin, A. (2005). Possible links between selfawareness and inner speech theoretical background, underlying mechanisms, and empirical evidence. Journal of Consciousness Studies, 12(4-5), 115-134. Recuperado de http://psycnet.apa.org/record/2005-064 93-007

Morin, A., \& Hamper, B. (2012). Selfreflection and the inner voice: Activation of the left inferior frontal gyrus during perceptual and conceptual self-referential thinking. The Open Neuroimaging Journal, 6, 78-89. http://dx.doi.org/10.2174/18744400 01206010078

McCafferty, S. (2004). Space for cognition: Gesture and second language learning. International Journal of Applied Linguistics, 
14(1), 148-165. http://dx.doi.org/10.1111/j $.1473-4192.2004 .0057 \mathrm{~m} . \mathrm{x}$

Mrazek, M., Phillips, D., Franklin, M., Broadway, J., \& Schooler, J. (2013). Young and restless: Validation of Mind Wandering Questionnaire reveals disruptive impact of mind wandering for youth. Frontiers in Psychology, 4, 1-7. http://dx.doi.org/10.3389 /fpsyg.2013.00560

Piaget, J. (1922). The language and thought of the child. Nueva York: Routledge Classics.

Risko, E. F., Anderson, N., Sarwal, A., Engelhardt, M., \& Kingstone, A. (2012). Everyday attention: Variation in mindwandering and memory in a lecture. Applied Cognitive Psychology, 26, 234-242. h ttp://dx.doi.org/10.1002/acp.1814

Roberts, J. (2008). Expressive free speech, the state and the public sphere: A BakhtinianDeleuzian analysis of 'Public Address' at Hyde Park. Social Movement Studies, 7(2), 101-119. http://dx.doi.org/10.1080/147428 30802283410

Rosenthal, V. (2012). La voix de l'intérieur. Intellectica, 2(58), 53-89. Recuperado de https://www.researchgate.net/publicatio n/259655458_La_voix_de_l'interieur

Ruby, F. J., Smallwood, J., Sackur, J., \& Singer, T. (2013). Is self-generated thought a means of social problem solving? Frontiers in Psychology, 4, 1-10. http://dx.doi.org/10.338 9/fpsyg.2013.00962

Seli, P., Risko, E., \& Smilek, D. (2016). On the necessity of distinguishing between unintentional and intentional mind wandering. Psychological Science, 27(5), 685-691. http://dx.doi.org/10.1177/ 0956797616634068

Smallwood, J., \& Schooler, J. W. (2006). The restless mind. Psychological Bulletin, 132, 946-958. http://dx.doi.org/10.1037/0033-2 909.132.6.946

Smallwood, J., Obsonsawin, M., Baracaia, S. F., Reid, H., O'Connor, R., \& Heim, D. (2003). The relationship between rumination, dysphoria, and self-referent thinking: Some preliminary findings. Imagination, Cognition and Personality, 22, 317-342. http://dx.doi.o rg/10.2190/2N80-AVM3-4A23-LEAJ

Sokolov, A. (1972). Inner speech and thought. Nueva York: Plenum.

Villagrán, M., Navarro, J., López, J., \& Alcalde, C. (2002). Pensamiento formal y resolución de problemas matemáticos. Psicothema, 14(2), 382-386. Recuperado de http://www.psicot hema.com/pdf/736.pdf

Vygotsky, L. (1934). Pensamiento y lenguaje. Madrid: A. Machado Libros.

Waldron, V. R., \& Cegala, D. J. (1992). Assessing conversational cognition: Levels of cognitive theory and associated methodological requirements. Human Communication Research, 18, 599-622. http://dx.doi.org/10.1111/j.14682958.1992.tb00573.x

Werner, H. (1955). A psychological analysis of expressive language. In On expressive language. Worcester: Clark University Press.

Werner, H. (1956). Microgenesis and Aphasia. Journal of Abnormal and Social Psychology, $52,347-353$

Werner, H. \& Kaplan, B. (1963). Symbol Formation. USA: Lawrence Erlbaum Associates Publishers.

Zurina, H., \& Williams, J. (2011). Gesturing for oneself. Educational Studies in Mathematics, 77(2), 175-188. http://dx.doi.org/10.1007/s 10649-010-9294-x

\section{Notas}

* Artículo de investigación. 